\title{
Carboxymethyl Cellulose (CMC) as a Template for Laccase-Assisted Oxidation of Aniline
}

\author{
Euijin Shim ${ }^{1}$, Jennifer Noro' ${ }^{2}$ Artur Cavaco-Paulo ${ }^{2,3}$, Hye Rim Kim ${ }^{1 *}$ and Carla Silva ${ }^{2 *}$ \\ ${ }^{1}$ Department of Clothing and Textiles, Sookmyung Women's University, Seoul, South Korea, ${ }^{2}$ Centre of Biological \\ Engineering, University of Minho, Campus of Gualtar, Braga, Portugal, ${ }^{3}$ International Joint Research Laboratory for Textile \\ and Fiber Bioprocesses, Jiangnan University, Wuxi, China
}

Polyaniline (PANi) is a conducting polymer which has been subject of intensive research on the exploitation of new products and applications. The main aim of the work is the development of a conductive bacterial cellulose (BC)-based material by enzymaticassisted polymerization of aniline. For this, we study the role of carboxymethyl cellulose

OPEN ACCESS

Edited by:

Susana Rodriguez-Couto, Independent Researcher, Vigo, Spain

Reviewed by: Peter Walde,

ETH Zürich, Switzerland Ashok Kumar,

Jaypee University of Information

Technology, India

Emilia Morallon,

University of Alicante, Spain

*Correspondence: Hye Rim Kim khyerim@sookmyung.ac.kr

Carla Silva

carla.silva@ceb.uminho.pt

Specialty section:

This article was submitted to

Industrial Biotechnology,

a section of the journal

Frontiers in Bioengineering and

Biotechnology

Received: 22 November 2019 Accepted: 16 April 2020 Published: 14 May 2020

Citation:

Shim E, Noro J, Cavaco-Paulo A

Kim HR and Silva C (2020)

Carboxymethyl Cellulose (CMC) as a Template for Laccase-Assisted

Oxidation of Aniline.

Front. Bioeng. Biotechnol. 8:438.

doi: 10.3389/fbioe.2020.00438
(CMC) as a template for the in situ polymerization of aniline. Bacterial cellulose was used as the supporting material for the entrapment of $\mathrm{CMC}$ and for the in situ oxidation reactions. The amount of $\mathrm{CMC}$ entrapped inside $\mathrm{BC}$ was optimized as well as the conditions for laccase-assisted oxidation of aniline. The new oligomers were evaluated by spectrometric techniques, namely ${ }^{1} \mathrm{H}$ NMR and MALDI-TOF, and the functionalized $\mathrm{BC}$ surfaces were analyzed by thermogravimetric analysis (TGA), Fourier-transform infrared spectroscopy (FTIR), X-ray diffraction (XRD), scanning electron microscope (SEM), and reflectance spectrophotometry. The conductivity of the developed materials was evaluated using the four-probe methodology. The oligomers obtained after reaction in the presence of $\mathrm{CMC}$ as template display a similar structure as when the reaction is conducted only in BC. Though, after oxidation in the presence of this template, the amount of oligomers entrapped inside $\mathrm{BC} / \mathrm{CMC}$ is considerably higher conferring to the material greater electrical conductivity and coloration. The use of CMC as a template for aniline oxidation on $\mathrm{BC}$ seems to be a promising and cheap strategy to improve the yield of functionalization and increment the properties of the materials, namely electrical conductivity and coloration.

Keywords: aniline, laccase, oxidation, template, carboxymethyl cellulose

\section{INTRODUCTION}

Conductive materials have been gaining scientific attention due to the increasing need for new technologies for the exploitation of electronic sensor devices, energy-storage, and intelligent clothing (Sapurina and Shishov, 2012). Bacterial cellulose (BC) has been used to develop composites containing a conductive polymer, such as polyaniline (PANi), polypyrrole and polythiophene, and others (Hu et al., 2011; Marins et al., 2011; Shim et al., 2019b). The use of templates, like sulfonated polystyrene as sodium salt (SPS), the calcium salt of ligninosulfonate, micelles composed by sodium dodecylbenzenesulfonate (SDBS), or vesicles made-up of sodium bis(2-ethylhexyl)sulfosuccinate (AOT) have been described as favoring the polymerization of aniline (Walde et al., 2019). These molecules are composed 
by sulfonate groups and, in oxidation conditions, aniline is oxidized to a conductive product, emeraldine salt (Walde et al., 2019). The templates, due to a localization of the reaction in their vicinity, direct the regioselectivity of the monomer coupling reaction, favoring para-over ortho-coupling of oxidized aniline. These compounds have dopant action (counter ions), which balance the positive charge on the PANi, thereby stabilizing the PANi-Emeraldine salt structure, crucial for electrical conductivity. Together with templates, the laccase $/ \mathrm{O}_{2}$ - assisted polymerization of aniline has been studied as an environmentally friendly route to produce conductive PANi (Streltsov et al., 2009). Laccase has been applied for the aniline polymerization in situ inside $\mathrm{BC}$ nano fibers under mild conditions replacing the chemical oxidants that are normally used, such as ammonium peroxydisulfate, potassium dichromate or ferric chloride (Shim et al., 2019a). The use of templates is crucial to reduce the undesired coupling reactions, as side-chain branching, and to ensure the polymerization of linear head-to-tail aniline (De Salas et al., 2016). The template works by forming polymerpolymer complexes which are stabilized via non-covalent binding forces among hydrogen bonds, electrostatic and hydrophobic interactions during polymerization (Kim et al., 2004; Yue et al., 2016).

Carboxymethyl cellulose (CMC), a soluble derivative of cellulose, is an example of an efficient template for aniline polymerization. It adsorbs irreversibly to cellulose fibers under specific conditions increasing their negative charge (Peng et al., 2012; Fu et al., 2015; Wang et al., 2016). CMC contains $-\mathrm{COO}^{-}$groups which supply anionic locations to react with electropositive molecules (positively charged cations) via electrostatic interactions, favoring the polymerization of aniline (Fu et al., 2015). BC has considerable amount of hydroxyl groups which, due to their high reactivity, can be easily modified. However, the reactivity of the hydroxyl groups can be restricted by intramolecular and intermolecular hydrogen bonds during polymerization events (Kim et al., 2004; Yue et al., 2016). When $\mathrm{CMC}$ is introduced inside $\mathrm{BC}$, the $-\mathrm{COO}^{-}$groups of $\mathrm{CMC}$ can form intermolecular interactions with the hydroxyl groups of $\mathrm{BC}$. The loss of some $-\mathrm{OH}$ groups by $\mathrm{BC}$, able to interact with other compounds, can be counterbalanced by the presence of CMC, which is composed by hydroxyl and carboxylate groups.

In this work, we developed conductive BC composites by entrapping $\mathrm{CMC}$ inside $\mathrm{BC}$ membranes followed by the in situ aniline polymerization by laccase. The CMC was entrapped inside $\mathrm{BC}$ to serve as template for polymerization and laccase was used as reaction catalyst. Potassium hexacyanoferrate (II) (KHCF), a radical initiator, and bis(2-ethylhexyl) sulfosuccinate sodium salt (AOT), a surfactant, were used as additives for aniline oxidation. The role of CMC on aniline polymerization was evaluated through the quantification of the amount of polymer formed. The polymerization of aniline was evaluated by UV/Visible spectroscopy and the new oligomers were characterized by spectrometric techniques, namely ${ }^{1} \mathrm{H}$ NMR and MALDI-TOF. BC/PANi and BC/CMC/PANi composites were monitored by FTIR, SEM, TGA, and XRD analysis. The conductivity of the developed materials was assessed through the four-probe method and the color of BC samples was evaluated spectrophotometrically.

\section{EXPERIMENTAL}

\section{Materials}

Glucose (Duksan Pure Chemicals Co., Seoul, South Korea) was used as carbon source. A mixture of yeast extract (Becton, Dickinson and Company, Sparks, Unitesd States) and peptone (Becton, Dickinson, Sparks, United States) were used as nitrogen sources. The following chemicals were used without further purification: acetic acid (Duksan Pure Chemicals Co., Seoul, South Korea), sodium acetate (Sigma, Saint Louis, MO, United States), hydrogen peroxide (Duksan Pure Chemicals Co., South Korea), aniline (Junsei Chemical Co. Ltd., Tokyo, Japan), KHCF (Fisher Scientific, Loughborough, United Kingdom), AOT (Tokyo Chemical Industry Co., Tokyo, Japan). Laccase (EC 1.10.3.2.) from Myceliophthora thermophila was obtained from Novozymes (Bagsvaerd, Denmark). Citric acid monohydrate (Sigma, Saint Louis, MO, United States), sodium phosphate dibasic dehydrate (Riedel-de Haën, Seelze, Germany), and CMC (Sigma, Saint Louis, MO, United States).

\section{Preparation of Bacterial Cellulose Samples}

The BC samples were produced and pretreated according to the methodology previously reported (Han et al., 2018). The Hestrin-Schramm (HS) medium was prepared adding glucose as carbon source $(20 \mathrm{~g} / \mathrm{L})$, to a mixture of yeast extract and peptone powder as the nitrogen source $(5 \mathrm{~g} / \mathrm{L}$ each). Both were added to distilled water and mixed until dissolution. Afterward the solution was boiled at $100^{\circ} \mathrm{C}$ for $10 \mathrm{~min}$. The scoby involving bacteria Acetobacter (acetic acid bacteria) was added into the $\mathrm{HS}$ medium for static cultivation at $26^{\circ} \mathrm{C}$ for 8 days. The BC samples were then recovered with $3 \% \mathrm{NaOH}$ solution at $25^{\circ} \mathrm{C}$ using shaking water bath at $50 \mathrm{rpm}$ for $90 \mathrm{~min}$, neutralized with distilled water adjusted to $\mathrm{pH} 3.0$ using acetic acid for $30 \mathrm{~min}$. In addition, the $\mathrm{BC}$ samples were bleached with a $5 \% \mathrm{H}_{2} \mathrm{O}_{2}$ solution at $90^{\circ} \mathrm{C}$ using a shaking water bath at $110 \mathrm{rpm}$ for $60 \mathrm{~min}$. After bleaching, the $\mathrm{BC}$ were dried in a drying convection oven (OF-21, Jeio tech Co.) at $35^{\circ} \mathrm{C}$ (Han et al., 2018).

\section{Entrapment of Carboxymethyl Cellulose Inside BC}

Firstly, BC was swelled with $8 \% \mathrm{NaOH}(\mathrm{v} / \mathrm{v})$ at $25^{\circ} \mathrm{C}$ for $30 \mathrm{~min}$. Afterward the samples were subjected to ultrasonication, using an ultrasonic bath, at $50^{\circ} \mathrm{C}$ for $5 \mathrm{~min}$. The $\mathrm{BC}$ was neutralized with $0.5 \%$ acetic acid (v/v) (Song et al., 2017).

Secondly, different concentrations of CMC $(15,45$, and $75 \mathrm{~g} / \mathrm{L})$ were dissolved in $20.0 \mathrm{~mL}$ of distilled water and the BC samples $\left(1.5 \mathrm{~cm}^{2}\right)$ added. The mixtures were placed in a water bath at $55^{\circ} \mathrm{C}$ for 2,5 , and $24 \mathrm{~h}$. After each period of incubation, the samples were placed in the fridge to stop the reaction, and then 
BC samples were rinsed repeatedly with distilled water. Finally, the $\mathrm{BC}$ samples containing entrapped CMC were freeze-dried (Sadeghi et al., 2012; Lin et al., 2014; Yue et al., 2016).

The entrapment ratio (ER) was determined using Eq. 1, where $W_{B C}$ is the weight of $B C ; W_{B C+C M C}$ is the weight of the sample after reaction $(\mathrm{BC}+\mathrm{CMC})$.

$$
\mathrm{ER}(\%)=\frac{W_{\mathrm{BC}+\mathrm{CMC}}-W_{\mathrm{BC}}}{W_{\mathrm{BC}}} \times 100
$$

The results obtained resulted from the mean of three independent experiments.

\section{In situ Laccase-Assisted Synthesis of Polyaniline on $\mathrm{BC}$ and $\mathrm{BC} / \mathrm{CMC}$}

The $\mathrm{BC}$ and $\mathrm{BC} / \mathrm{CMC}$ samples were placed in a $100 \mathrm{~mL}$ flask containing a mixture of $25 \mathrm{U} / \mathrm{mL}$ of laccase, $5 \mathrm{mM}$ of AOT, $10 \mathrm{mM}$ of $\mathrm{KHCF}$ and $50 \mathrm{mM}$ of aniline, in a final volume of $20 \mathrm{~mL}$ of $0.1 \mathrm{M}$ acetate buffer $(\mathrm{pH} 4)$. The reactional mixtures were covered with foil, allowing the oxygen entrance, and stirred for $24 \mathrm{~h}$ at room temperature, in a water bath (Grant, United Kingdom) under shaking. The time of reaction was established according to procedures from literature (Shumakovich et al., 2012; De Salas et al., 2016). At the end of each experiment, the BC samples were washed thoroughly with water to remove the by-products and the remaining starting reagents. The excess of water was removed with filter paper. Afterward the BC samples coated with PANi were dried in a convection oven (OF-21, Jeio tech Co.) at $35^{\circ} \mathrm{C}$ for $24 \mathrm{~h}$.

\section{Polymers Characterization UV/Visible Spectroscopy}

The polymerization of aniline was followed by UVVisible spectroscopy using a 96-quartz microplate reader (SynergyMx, Shimadzu, Japan) in the wavelength range of $230-800 \mathrm{~nm}$.

\section{${ }^{1} \mathrm{H}$ NMR and MALDI-TOF}

The ${ }^{1} \mathrm{H}$ NMR spectroscopy of PANi was determined using a Bruker Avance $400(400 \mathrm{MHz}) . \mathrm{CDCl}_{3}$ was used as deuterated solvent, using the peak solvent as internal reference. Chloroform was chosen given that it demonstrated the best ability to solubilize most of the reactional content (Shah et al., 2019). The polymer products obtained were also characterized by MALDI-TOF mass spectrometry using a Bruker Autoflex Speed instrument (Bruker Daltonics $\mathrm{GmbH}$ ) equipped with a $337 \mathrm{~nm}$ nitrogen laser. The matrix solution for MALDI-TOF measurements was prepared by dissolving a saturated solution of 2,5-dihydroxybenzonic acid (DHB) in TA30 solution or a saturated solution of $\alpha$-cyano-4hydroxycinnamic acid (CHCA). Samples were spotted onto a ground steel target plate (Bruker part $n^{\circ} 209519$ ) and analyzed in the linear negative mode by using factory-configured instrument parameters suitable for a $0.4-4 \mathrm{kDa} m / z$ range (ion source 1: $19.5 \mathrm{kV}$; ion source 2: $18.3 \mathrm{kV}$ ). The time delay between laser pulse and ion extraction was set to $130 \mathrm{~ns}$, and the laser frequency was $25 \mathrm{~Hz}$. The $M_{n}$ (number-average molecular weight) and
$M_{w}$ (weight-average molecular weight) of PANi obtained after oxidation was obtained by MALDI-TOF direct analysis and according to the equations:

$$
\begin{gathered}
M_{n}=\sum n_{i} M_{i} / \sum n_{i} \\
M_{w}=\sum n_{i} M_{i}^{2} / \sum n_{i} M_{i} \\
\mathrm{PDI}=M_{w} / M_{n} \\
\mathrm{DP}_{\mathrm{avg}}=M_{n} /[\mathrm{M}]
\end{gathered}
$$

Where $n_{i}$ is the relative abundance of each peak; $M_{i}$ is the $m / z$ correspondent to each peak (Su et al., 2017), and [M] is the molecular weight of the repeating unit.

\section{$\mathrm{BC}$ and $\mathrm{BC} / \mathrm{CMC}$ Surface Coating Characterization}

\section{FTIR-ATR}

To analyze the chemical structure of $\mathrm{BC}$ and $\mathrm{BC} / \mathrm{CMC}$ functionalized with PANi, FTIR-ATR spectra were acquired using an ATR FTIR, IRAffinity-1S (SHIMADZU). 45 scans were completed between 4000 and $400 \mathrm{~cm}^{-1}$ at a resolution of $8 \mathrm{~cm}^{-1}$. Baselines for each sample spectrum were normalized using spectrum software.

\section{X-Ray Diffraction}

The changes on the structure of $\mathrm{BC}$ and BC/CMC samples when coated with PANi were investigated by X-ray diffraction (XRD) using a New D8-ADVANCE (multi-purpose diffractometer, Bruker-AXS, Fitchburg, United States). X-ray diffraction patterns were recorded at the CuKa radiation wavelength of $1.542 \AA$ and generated at a voltage of $40 \mathrm{kV}$ and a filament emission of $40 \mathrm{~mA}$. Samples were scanned in the range from $5^{\circ}$ to $40^{\circ}$ at a scan speed of $1 / \mathrm{min}$. The crystallinity index (CI) was calculated from the height ratio between the intensity of the crystalline peak that is sum of crystalline area $\left(I_{002}-I_{a m}\right)$ and the total intensity that means the sum of crystalline and amorphous area $\left(I_{002}\right)$ after subtraction of the background signal measured without BC, following the equation (Lopes et al., 2014; Miyamoto et al., 2014; Mohammadkazemi et al., 2015; Han et al., 2018):

$$
\mathrm{CI}=\frac{I_{002}-I_{\mathrm{am}}}{I_{002}}
$$

where $I_{200}$ is the overall intensity of the peak at $2 \theta$ and $I_{a m}$ is the intensity of the base line at $2 \theta$.

\section{Thermal Analysis}

Thermogravimetric analysis (TGA) measurements of the BC and BC/CMC functionalized samples were carried out in a Perkin Elmer, TGA 4000 equipment, using about approximately 8-10 $\mathrm{mg}$ samples over the temperature range, $0-800^{\circ} \mathrm{C}$ at a heating rate of $10^{\circ} \mathrm{C} / \mathrm{min}$ under a nitrogen flow of $20 \mathrm{~mL} / \mathrm{min}$. Thermogravimetric analysis was made with the nanocomposite films placed in a high quality nitrogen (99.5\% nitrogen, $0.5 \%$ 
oxygen content) atmosphere to prevent unwanted oxidation. The weight loss calculations were performed considering the main decomposition steps obtained by the DTG curves shown in supporting information (Supplementary Figure S1).

\section{Scanning Electron Microscopy}

The coated $\mathrm{BC}$ and $\mathrm{BC} / \mathrm{CMC}$ samples were characterized using a desktop scanning electron microscope (SEM) coupled with EDS (energy-dispersive X-ray spectroscopy) detector (PhenomWorld BV, Netherlands). All results were acquired using the ProSuite software integrated with Phenom Element Identification software, allowed for the quantification of the concentration of the elements present in the samples, expressed in either weight or atomic concentration. Prior to SEM analysis the samples were added to aluminum pin stubs with electrically conductive carbon adhesive tape (PELCO Tabs ${ }^{\mathrm{TM}}$ ), with the excess removed using compressed air. Samples were coated with $2 \mathrm{~nm}$ of $\mathrm{Au}$ for improved conductivity. The aluminum pin stub was then placed inside a Phenom Standard Sample Holder, and different points for each sample were analyzed for elemental composition.

\section{Color Evaluation by Reflectance Spectrophotometry}

The color data for the dried samples was determined using a CCM system (JX-777, Japan) and illuminant $\mathrm{D}_{65}$ with a $10^{\circ}$ standard observer. The color strength $(K / S)$ was calculated from the reflectance values using the Kubelka-Munk equation (Shim and Kim, 2019).

$$
K / S=(1-R)^{2} / 2 R
$$

where $R$ is the reflectance, expressed as a proportional value; $K$ is the absorption coefficient; and $S$ is the light-scattering coefficient. The $K / S$ values were presented as checksum $K / S$ (sum of all $K / S$ values corresponding to all wavelengths). All measurements were performed at least 10 times. The $K / S$ values are directly proportional to the sample coloration.

\section{Conductivity of BC and BC/CMC Coated Samples}

The electrical conductivity of coated samples was measured with a CMT-series (Changmin Tech Co., Ltd.) using four-point probe technique placing them under a pre-defined distance between. The conductivity was calculated according to the following equation:

$$
\text { Conductivity }(\sigma)=1 / \rho\left(\mathrm{S} \mathrm{m}^{-1}\right)
$$

Resistivity can be calculated with $\rho=2 \pi S(V / I)$, where $S$ is the probe spacing $(\mathrm{mm})$, which was kept constant, $I$ is the supplied current in microamperes, and the $V$ is corresponding voltage measured in millivolts (Yue et al., 2016).

\section{RESULTS AND DISCUSSION}

\section{CMC as Template for Aniline Polymerization \\ Optimization of CMC Entrapment}

Figure 1 shows the entrapment yield of CMC inside BC using different reaction conditions. The data reveal that after $5 \mathrm{~h}$ the entrapment of CMC is directly proportional to the concentration

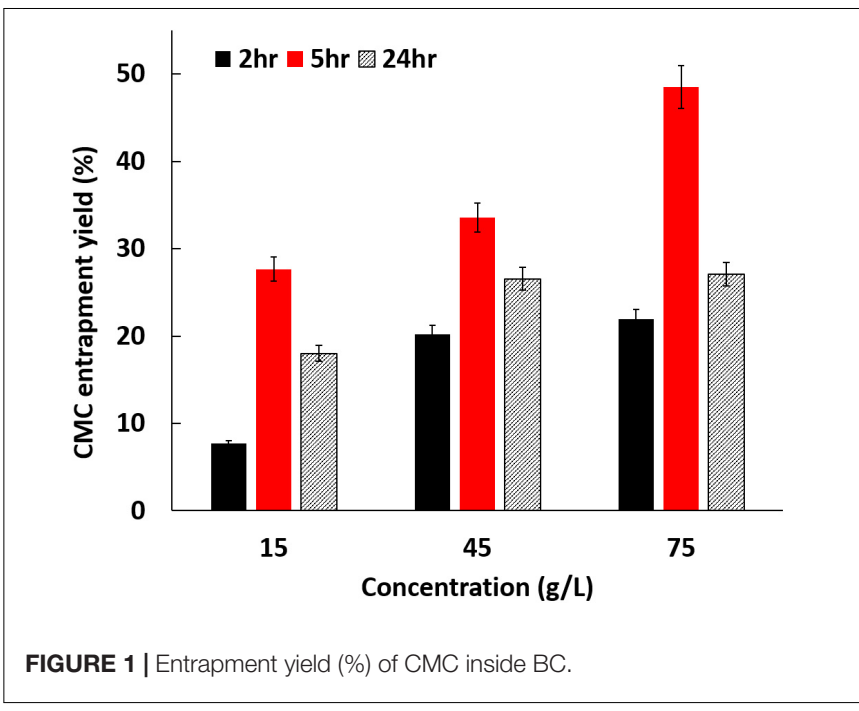

used, being achieved close to $50 \%$ of material entrapment for $75 \mathrm{~g} / \mathrm{L}$ of CMC. For the other incubation periods tested (2 and $24 \mathrm{~h}$ ) the data reveal this proportionality for 15 and $45 \mathrm{~g} / \mathrm{L}$, however reaching a saturation plateau for the highest concentration, $75 \mathrm{~g} / \mathrm{L}$. The time was also optimized, and the results demonstrate that $5 \mathrm{~h}$ is the ideal time to achieve the highest levels of entrapment. Until $5 \mathrm{~h}$ the entrapment increases, independently on the initial concentration of $\mathrm{CMC}$, decreasing thereafter for prolonged periods of exposition of BC to CMC. From this data one may assume that from a certain period of time the bonding between CMC and the $\mathrm{BC}$ available groups can weaken with the incubation time, due to the high affinity of water to BC (Ballesteros et al., 2018). Regardless this event, one could confirm that, after complex BC/CMC isolation from the medium, no further release of CMC is observed, even during polymerization reaction.

\section{The Role of CMC as Template During Aniline Polymerization}

The use of laccase for the polymerization of aniline is considered a green methodology comparing to the traditional approaches (Shim et al., 2019a). Su et al. (2018) used laccase from M. thermophila for the in situ polymerization of aniline into cotton, producing a conductive fabric. A similar approach was described by Zhang et al. (2016) which have used laccase from Aspergillus for the functionalization of cotton with PANi.

We previously observed the role of two different additives (AOT and KHCF) on the in situ polymerization of aniline in BC (Shim et al., 2019a).

Herein, in order to evaluate the role of CMC as template for aniline polymerization, several laccase-assisted reactions were conducted in the presence of additives and CMC as template. Table 1 presents the percentage of polymer conversion yield increment after aniline polymerization in the presence of CMC and other additives under free solution conditions without $\mathrm{BC}$ as support. Comparing the results obtained in the presence of $\mathrm{CMC}$, the polymer conversion is higher for all the reaction conditions tested. The role of the template is less pronounced for samples 
TABLE 1 | Percentage of oligomer/polymer conversion yield increment (\%) after polymerization of aniline in presence of $\mathrm{CMC}$ under different conditions (calculated from weight of polymer obtained after oxidation and subsequent washing).

\begin{tabular}{lc}
\hline Polymerization conditions & Polymer conversion (\%) \\
\hline Aniline + LAC + NO CMC & - \\
Aniline + LAC + CMC & 6 \\
Aniline + LAC + AOT + NO CMC & - \\
Aniline + LAC + AOT + CMC & 9 \\
Aniline + LAC + KHCF + NO CMC & - \\
Aniline + LAC + KHCF + CMC & 10 \\
Aniline + LAC + AOT + KHCF + NO CMC & - \\
Aniline + LAC + AOT + KHCF + CMC & 14 \\
\hline
\end{tabular}

oxidized only in the presence of laccase whereas when the laccaseassisted reaction was conducted using CMC in the presence of both additives, KHCF and AOT, the polymer conversion reaches the highest increase (14\%). We have previously reported that the synthesis of green PANi (emeraldine salt) could by incremented by the inclusion of additives like sodium bis (2-ethyl hexyl) sulfosuccinate (AOT) and KHCF in the medium (Shim et al., 2019a). Considering the previous and the present data one may predict a synergistic effect between both dynamic systems tested (AOT and CMC; Table 1). However, and since the role of AOT and KHCF were previously discussed, only CMC is highlighted herein (Shim et al., 2019a).

These results lead us to the next step of the work by conducting the same experiments using $\mathrm{BC}$ as support. In Table 2 is presented the relative yield of polymerization using $\mathrm{BC}$ and $\mathrm{BC} / \mathrm{CMC}$ as support for polymerization, showing the relative percentage of polymer detected, as in the reaction solution or inside the BC network. From the results presented it is perceptible that when CMC is entrapped inside BC and used as polymerization template, the amount of polymer inside the $\mathrm{BC}$ network is higher than when the polymerization is conducted using BC without CMC. It seems clear the role of $\mathrm{CMC}$ as template for aniline polymerization for the production of oligomers/polymers which remained solubilized or dispersed inside the porous $\mathrm{BC}$ membrane without precipitation. The considerable amount of $-\mathrm{COO}^{-}$groups of CMC impart to $\mathrm{BC}$ a negative character able to retain higher amount of positive PANi (Lin et al., 2015; Wang et al., 2016; Gautam et al., 2018). Being a macromolecular template, polyanion, able of undergoing electrostatic interactions with $\mathrm{PANi}$, it provides the ideal template for the polymer organization incrementing the amount of polymer entrapped inside BC. The role of CMC as template is distinguishable from the role of an additive since the polymer stays entrapped inside the $\mathrm{BC}$ material, even after washing. A scheme representative of the interactions between $\mathrm{BC} / \mathrm{CMC} / \mathrm{PANi}$ is proposed (Scheme $\mathbf{1}$ ).

\section{Following Enzymatic Polymerization of Aniline by UV-Visible Spectroscopy}

Figure 2 displays the UV-visible spectra of the reaction solutions after aniline polymerization under different conditions. After reaction, the high amount of material entrapped inside the
$\mathrm{BC}$ fibrils and at their surface, imparts high coloration to $\mathrm{BC}$ samples, being that only a low content of soluble oligomers can be detectable by UV/Visible spectroscopy. All the reaction mixtures changed from colorless to dark green during laccase-catalyzed polymerization of aniline in water bath.

The UV-visible spectra of the green PANi synthesized using template/aniline evidences the typical absorption bands of emeraldine salt at $420 \mathrm{~nm}$, distinguishing the semiquinoid radical cation, and at $700 \mathrm{~nm}$, the characteristic signal of doped PANi due to $\pi$-semi-polaron electronic transitions (Norris et al., 2000).

The spectra shows a similar profile for reactions conducted in the presence or in the absence of CMC. This might indicate that the type of oligomers/polymers obtained are similar, increasing, however, the amount of polymer entrapped on BC when CMC is used as template. The data gives an indication of the positive role of $\mathrm{CMC}$ as potentiating the oxidation leading to the polymerization of higher amount of polymer, as on soluble and/or insoluble form. The data also reveal that the new oligomers are detectable only in the presence of laccase as catalyst.

\section{Characterization of the Oligomers/Polymers Obtained After Laccase-Assisted Oxidation ${ }^{1} \mathrm{H}$ NMR Analysis}

In Figure 3 it is depicted the ${ }^{1} \mathrm{H}$ NMR spectra obtained after in situ reaction on $\mathrm{BC}$, under different conditions, in the absence (A) and in the presence of CMC (B). The data show that the use of a template to perform the reactions, does not interfere with the structure of the polymer formed. A similar structure is obtained, as in absence or in presence of CMC, as it can be seen by the assignment of the peaks at the same chemical shift and with the same pattern. These results clearly indicate that the catalytic activity and selectivity of laccase is not influenced by the presence of the template. In both cases $(\mathrm{BC}$ or $\mathrm{BC} / \mathrm{CMC})$, it is observed a set of new doublets (between $\delta_{H} 7.0$ and $7.7 \mathrm{ppm}$ ), with coupling constants of $J=8 \mathrm{~Hz}$ and $J=2 \mathrm{~Hz}$, which correspond to the ortho and meta coupling, respectively. These values are in agreement with the PANi structure proposed (Figure 3), which indicates that is para-substituted. We have also observed that the polymer conversion using BC is $100 \%$ for almost all conditions tested, with exception of aniline + laccase (Figure 3A,ii); or aniline + AOT (Figure 3A,v), evidenced by the peaks $\mathbf{a}$ and $\mathbf{c}$, which appear at a different chemical shift, respecting the control spectra, due to the presence of the polymer in the medium. In the presence of CMC, a full conversion of the aniline monomer is observed for all the conditions tested.

The different oligomeric species of PANi obtained, may have differentiated solubility. By ${ }^{1} \mathrm{H}$ NMR, we only observe small oligomeric species, confirmed by the peak's integration. The results obtained represent only the soluble fraction of the oligomers in the deuterated solvent.

\section{MALDI-TOF}

The MALDI-TOF analysis was conducted to determine the degree of polymerization of PANi. Figure 4 shows the 
TABLE 2 | Yield of polymerization of aniline in the presence of additives inside BC and BC/CMC (calculated from weight of polymer obtained after oxidation).

\begin{tabular}{|c|c|c|c|c|c|}
\hline & \multirow{2}{*}{$\begin{array}{l}\text { Control solution } \\
\text { without BC }\end{array}$} & \multicolumn{2}{|c|}{ BC (without CMC) } & \multicolumn{2}{|c|}{$\mathrm{BC} / \mathrm{CMC}$} \\
\hline & & Polymer in BC (\%) & Polymer in solution (\%) & Polymer in BC (\%) & Polymer in solution (\%) \\
\hline Aniline + LAC & 100 & 34 & 66 & 54 & 46 \\
\hline Aniline + AOT + LAC & & 35 & 65 & 60 & 40 \\
\hline Aniline + AOT + No LAC & & - & - & - & - \\
\hline Aniline + KHCF + LAC & & 36 & 64 & 62 & 38 \\
\hline Aniline + KHCF + No LAC & & 14 & 84 & 70 & 30 \\
\hline Aniline + AOT + KHCF + LAC & & 44 & 56 & 53 & 47 \\
\hline Aniline + AOT + KHCF + No LAC & & 36 & 64 & 62 & 38 \\
\hline
\end{tabular}

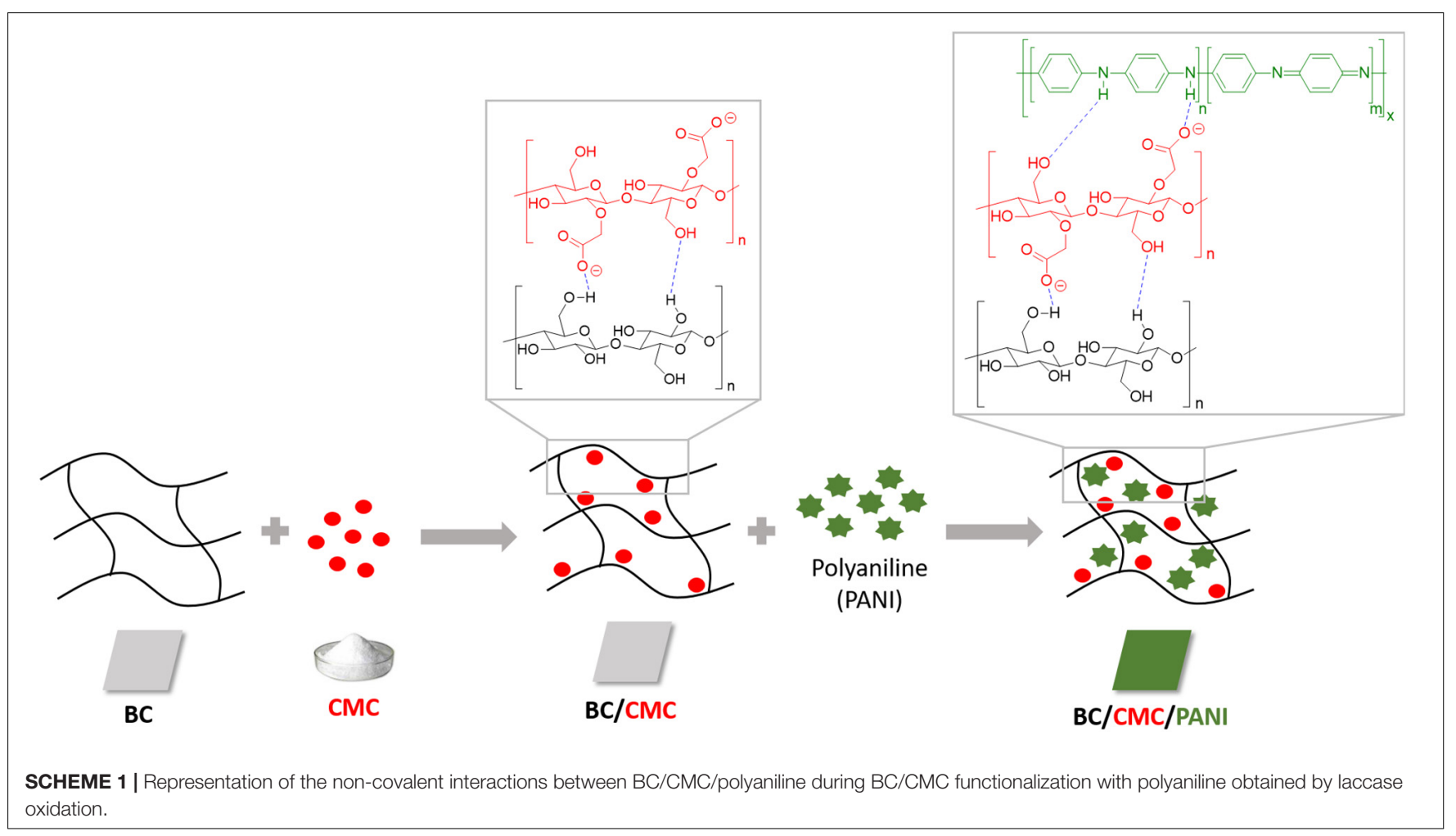

MALDI-TOF spectra of PANi produced after in situ reaction on $\mathrm{BC}$ under different conditions in the absence and in the presence of CMC. The mass spectra of BC/PANi shows peaks between 189 and $3038 \mathrm{~m} / z$, whereas the spectra of BC/CMC/PANi display peaks between 268 and $2685 \mathrm{~m} / z$. Considering the monomer unit of PANi $\left(\mathrm{C}_{6} \mathrm{NH}_{5}\right)=93$, the peaks found might be attributed to aniline dimers, trimers, and tetramers. Looking to both spectra, it can be seen that longer polymers are detected on the reaction solution, in the absence of CMC. When this compound is used as template, the longer oligomers/polymers might be entrapped inside BC and not accessible for detection.

Table 3 displays the characterization of the oligomers/ polymers after oxidation and isolation, calculated from MALDI-TOF data analysis. The data confirms the occurrence of oligomers and polymers after aniline laccase-assisted polymerization since low and high molecular mass polymeric fractions were detected. We have detected oligomerization degrees of up to 33 residues in the PANi obtained in the presence of AOT and laccase and up to nine residues in the soluble green products obtained in the presence of KHCF. However, the average DP obtained corresponded to oligomers with a maximum of 13 units of aniline. These results have been found previously by us when conducting the experiments in the presence of additives (KHCF and AOT) in the absence of template (Shim et al., 2019a). Herein, our goal was to infer if the use of a template like CMC would influence the degree of polymerization. From the data obtained it seems that it is not the case, similar DPs are achieved when the experiments are conducted in the presence of CMC as template. However, data from Table 2 and other results like stronger coloration and conductivity, lead 


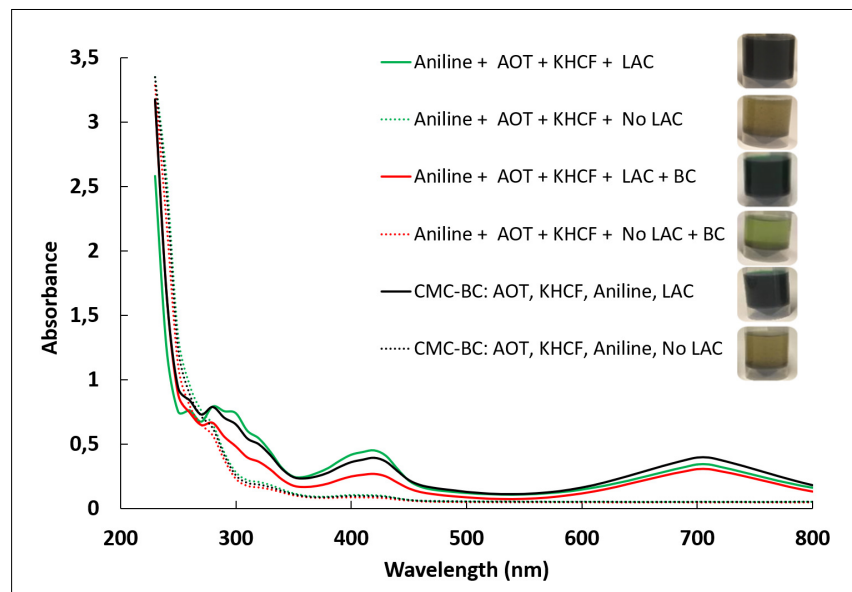

FIGURE 2 | UV-Visible spectra of polyaniline solutions in the presence of template $(\mathrm{CMC})$.

us to assume that higher amount of polymer is entrapped inside $\mathrm{BC}$ which, due to mobility constrains, are not released to the reaction solution, remaining inside the $\mathrm{BC}$ network. A higher amount of conductive polymer inside the porous support material is expected to confer greater electric conductivity.

\section{FTIR}

FTIR-ATR spectra for BC and BC/CMC functionalized with PANi under different conditions are presented in Supplementary
Figure S2. The BC spectra contains all the peaks characteristic of cellulose (Jasim et al., 2017), showing the typical peak of the intramolecular hydrogen bond at $3340 \mathrm{~cm}^{-1}$, and the C$\mathrm{O}$ stretching vibration region at $1045 \mathrm{~cm}^{-1}$ (Feng et al., 2012). After entrapment of CMC inside cellulose nanofibers, the band at $3348 \mathrm{~cm}^{-1}$ became broader, as can be evidenced by the BC/CMC spectrum (Supplementary Figure S2; Basavaraja et al., 2013). This spectrum shows strong absorption bands at 3348 , 2931 and $1059 \mathrm{~cm}^{-1}$ corresponding to the characteristic O$\mathrm{H}$ stretching vibrations of CMC (Pushpamalar et al., 2006; Fu et al., 2015; Kotresh et al., 2016). The absorption peak of PANi at $1565 \mathrm{~cm}^{-1}$ due to $\mathrm{C}=\mathrm{C}$ stretching deformation of quinoid rings stretching deformations, can be detected (Supplementary Figure S2); Peng et al., 2012; Kotresh et al., 2016). The spectra of PANi obtained without laccase (b3) and with laccase (b2) reveal a similar profile, indicating that PANi is produced even without catalyst in the presence of molecular oxygen. Moreover, these findings have been previously demonstrated through UV/Vis spectra. The PANi formed in the absence of laccase resulting from oxidation is not easily detectable by UV/Vis spectra since this technique is only able the measure soluble samples. However, from the images supplied in Figure 2, it is possible to detect coloration of the samples even in the absence of the catalysts, which confirms our findings. The presence of the additives played herein a crucial role, as previously confirmed by De Salas et al. (2016) that observed the aniline oxidation only in the presence of both AOT and KHCF additives, confirming the complete or partial doping. $\mathrm{BC} / \mathrm{PANi}$ have equal quinoid and benzoid units, as indicated by their similar band intensities, owning a conductive-like structure

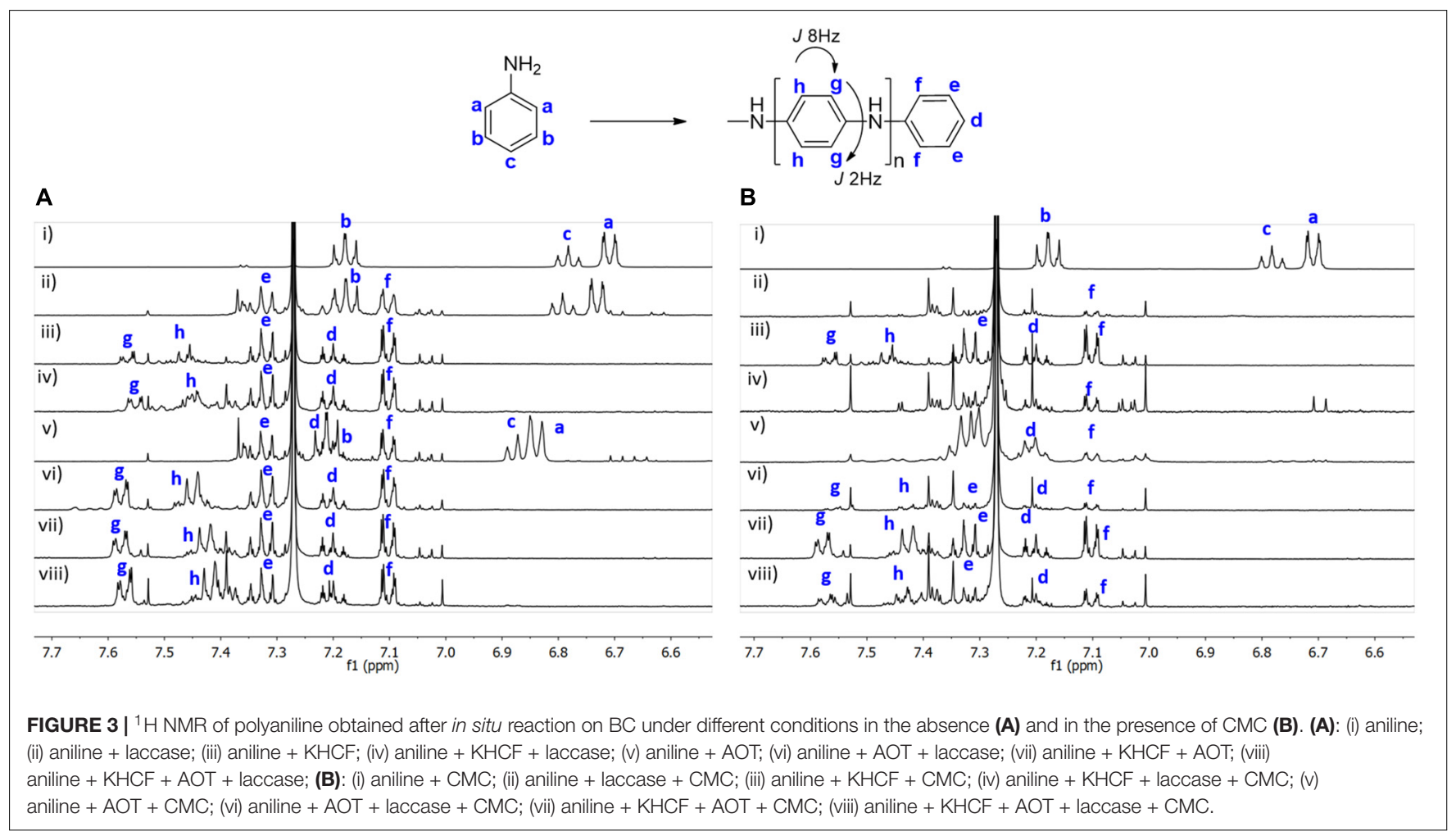




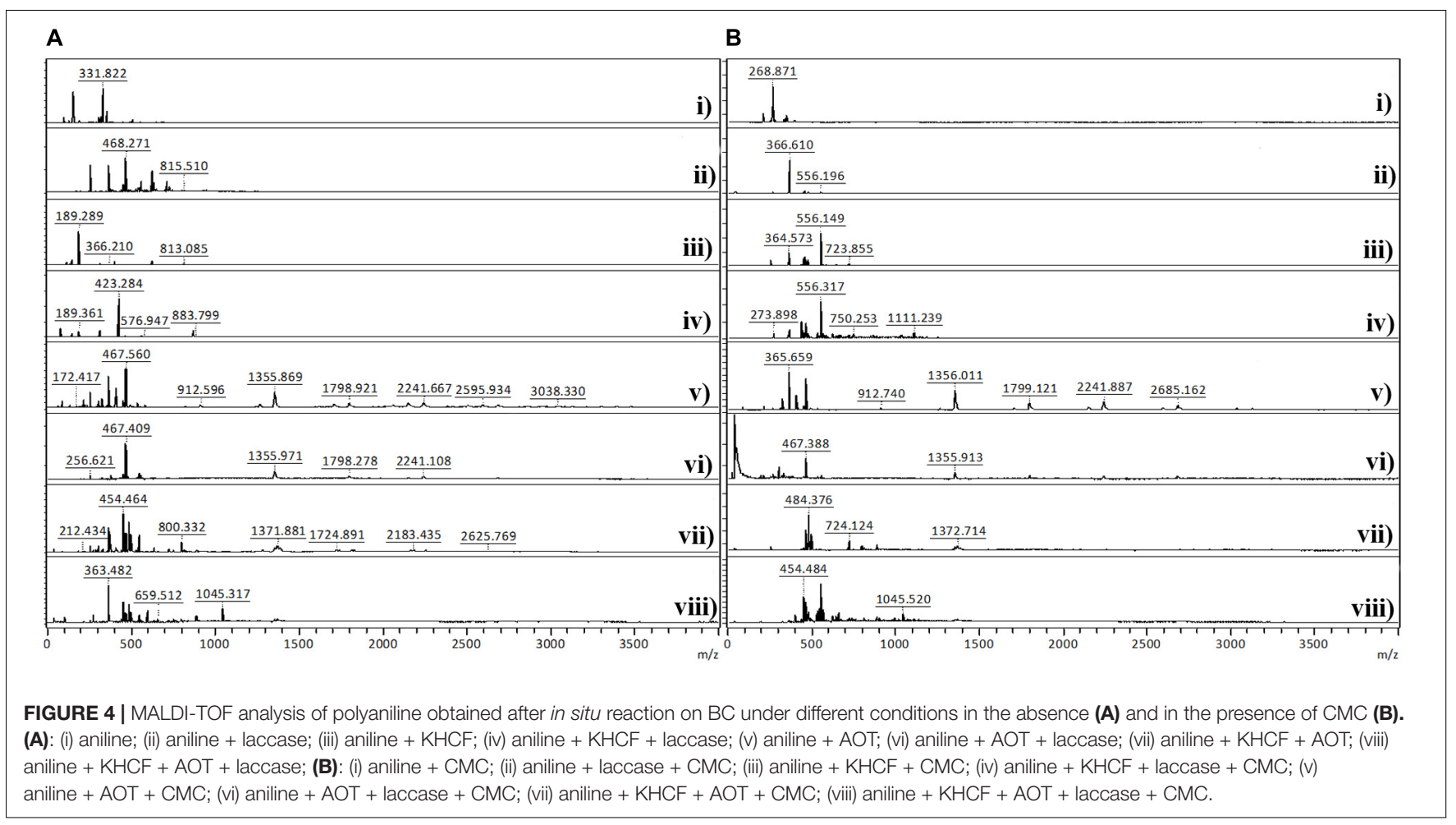

TABLE 3 | Polyaniline characterization in terms of $M n, M w$, average polymerization degree (DPavg) and maximum degree of polymerization (DP max) after laccase oxidation on $\mathrm{BC}$ and on BC/CMC under different conditions (the data is obtained from MALDI-TOF analysis; aniline (Mw) = 93,13 $\mathrm{g} / \mathrm{mol}$ ).

\begin{tabular}{|c|c|c|c|c|c|c|c|c|c|c|}
\hline & \multicolumn{2}{|c|}{$M_{n}$} & \multicolumn{2}{|c|}{$M_{w}$} & \multicolumn{2}{|c|}{ PDI $\left(M_{w} / M_{n}\right)$} & \multicolumn{2}{|c|}{$\mathrm{DP}_{\text {avg }}$} & \multicolumn{2}{|c|}{$\mathrm{DP}_{\max }$} \\
\hline & BC & $\mathrm{BC} / \mathrm{MC}$ & $\mathrm{BC}$ & $\mathrm{BC} / \mathrm{CMC}$ & BC & $\mathrm{BC} / \mathrm{CMC}$ & BC & $\mathrm{BC} / \mathrm{CMC}$ & BC & $\mathrm{BC} / \mathrm{CMC}$ \\
\hline Aniline + LAC & 477 & 384 & 530 & 391 & 1.1 & 1.0 & 5 & 4 & 10 & 7 \\
\hline Aniline + KHCF + LAC & 593 & 485 & 633 & 517 & 1.1 & 1.1 & 6 & 5 & 9 & 9 \\
\hline Aniline + KHCF + No LAC & 645 & 656 & 767 & 764 & 1.2 & 1.2 & 7 & 7 & 15 & 12 \\
\hline Aniline + AOT + LAC & 1092 & 1114 & 1808 & 1753 & 1.7 & 1.6 & 12 & 12 & 33 & 31 \\
\hline Aniline + AOT + No LAC & 876 & 1172 & 1470 & 1805 & 1.7 & 1.5 & 10 & 13 & 29 & 29 \\
\hline Aniline + KHCF + AOT + LAC & 702 & 659 & 1123 & 803 & 1.6 & 1.2 & 8 & 7 & 29 & 15 \\
\hline Aniline + KHCF + AOT + No LAC & 599 & 657 & 718 & 755 & 1.2 & 1.1 & 7 & 7 & 15 & 15 \\
\hline
\end{tabular}

The values were obtained using the equations previously detailed in the methods section.

which would confer to $\mathrm{BC}$ or $\mathrm{BC} / \mathrm{CMC}$ functionalized materials conductive properties.

\section{X-Ray Diffraction}

The XRD spectra of the extended linear scanning (10$60^{\circ}$ ) of $\mathrm{BC}$ and $\mathrm{BC} / \mathrm{CMC}$ functionalized with PANi is shown in Supplementary Figure S3. This technique will give some information concerning the structural changes in the microstructure of BC. Crystallinity and strength of hydrogen bonding accounts in the microstructure of this material. The XRD spectrum of $B C$ show peaks at $2 \theta=22.9-23.2^{\circ}$, the typical profile of cellulose I, assigned to the atomic plane of $\left[\begin{array}{lll}2 & 0 & 0\end{array}\right]$ of cellulose crystallite (Bhadra et al., 2009; Feng et al., 2012; Yousefi et al., 2013). When BC is modified with CMC, this peak appears more clearly and prominently, while BC/PANi composite showed an additional peak at $2 \theta=11.5^{\circ}$. This peak results from a decrease in the extent of ordered cellulose due to a weak acidic degradation (Jasim et al., 2017). In addition, the peak of polymer composites detected around $2 \theta=32.8^{\circ}$ and $34.9^{\circ}$ (Supplementary Figure S3, a2 and b2) corresponding to diffractions of $\left(\begin{array}{lll}3 & 0 & 0\end{array}\right)$ and (2 0 2 2), respectively (Wan et al., 2006). The crystallite size is estimated from the half width for the $\left(\begin{array}{lll}2 & 0 & 0\end{array}\right)$ diffraction as previously described (Yamamoto et al., 1996). From the results obtained one can observe that when $\mathrm{BC}$ and $\mathrm{BC} / \mathrm{CMC}$ were functionalized with oligomer/polymers, the composites present higher crystallinity and crystallite size (Supplementary Tables S1, S2). Crystallinity of BC/CMC materials is, however, lower than BC. The decrease of crystallinity upon CMC entrapment is associated to the split of the broadening 


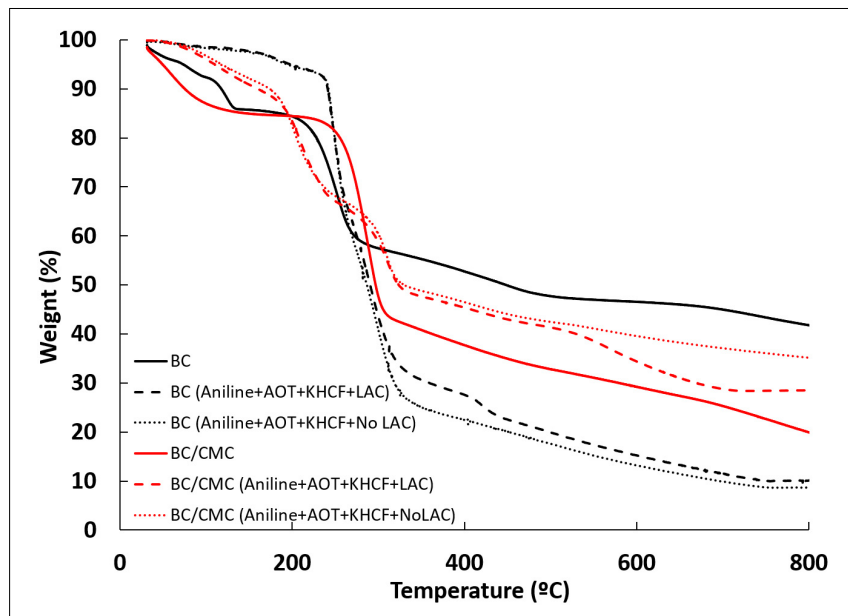

FIGURE 5 | TGA analysis of BC and BC/CMC materials functionalized with polyaniline under different conditions.

hydrogen bonds resulting from the carboxymethyl replacement at the hydroxyl groups of cellulose (Casaburi et al., 2018). The CMC remains between the cellulose ribbons hindered their approaching and preventing crystallization (Chen et al., 2014). It is assumed that the carboxymethylated BC lead to the increase of the amorphous parts, which also offers to BC/CMC higher adsorption capacity (Chen et al., 2009). In the case of $\mathrm{BC}$ and $\mathrm{BC} / \mathrm{CMC}$ functionalized with $\mathrm{PANi}$, the crystallinity increases, as the polymer chains ordering and regularity increases. The increase of the crystallinity might be attributed to the interaction of the PANi with the $-\mathrm{OH}$ groups of $\mathrm{BC}$ or $\mathrm{CMC}$, resulting in a uniform distribution of the polymer (Supplementary Table S1).

\section{Thermal Degradation Stability}

The TGA curves of BC composites are shown in Figure 5. Regarding the controls, $\mathrm{BC}$ and $\mathrm{BC} / \mathrm{CMC}$ have a similar thermal degradation until $300^{\circ} \mathrm{C}$, losing near $45 \%$ of weight. At $800^{\circ} \mathrm{C}$, the complex loses almost all the initial weight $(80 \%)$, whereas $\mathrm{BC}$ loses $60 \%$ of the weight. BC structure may be more robust than when CMC is entrapped, due to the release of water content when the entrapment occurs. Therefore, this event could lead to a change in the packing of the cellulose chains of $\mathrm{BC}$, inducing some loss of its thermostability.

In all the cases presented, the first degradation stage is related to the presence of moisture in the samples (Müller et al., 2012) and the second stage of weight loss occurring at $300^{\circ} \mathrm{C}$ is due to the thermal-oxidative degradation of the PANi structure and loss of small molecules (Gautam et al., 2018). When the materials are functionalized with $\mathrm{PANi}$, the thermal behavior of $\mathrm{BC}$ and $\mathrm{BC} / \mathrm{CMC}$ differs. BC/CMC functionalized with $\mathrm{PANi}$ present higher stability from up to $300^{\circ} \mathrm{C}$ (red dot and dash lines) than comparing to the respective control (red full line), attributed to the integrated compact morphology of the composites. A stronger interaction among all components of the materials, could led to a higher thermostability. As observed when CMC is entrapped inside

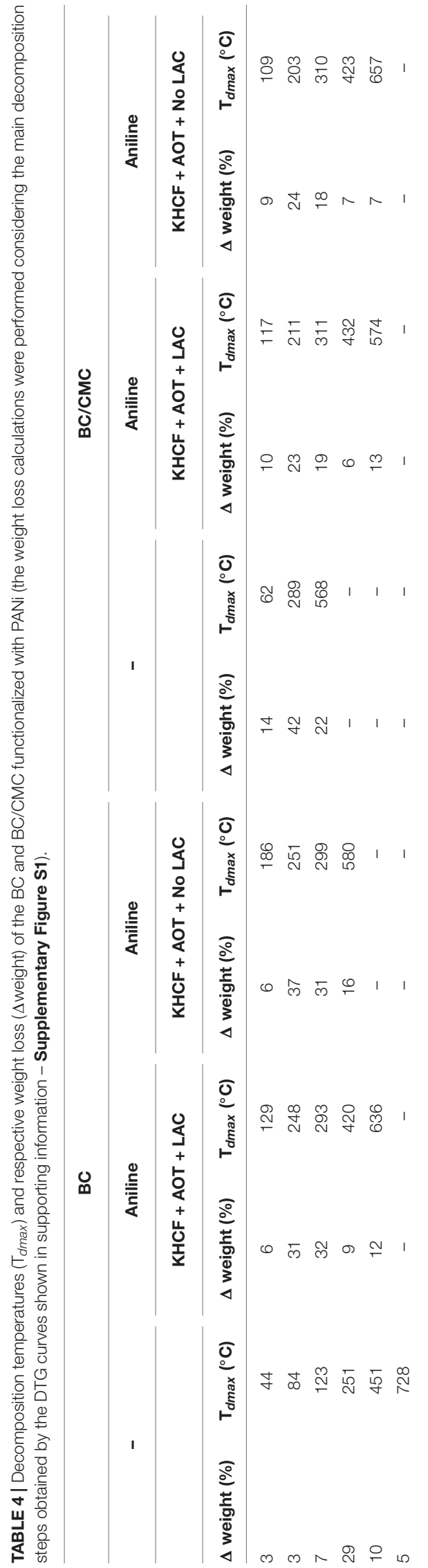




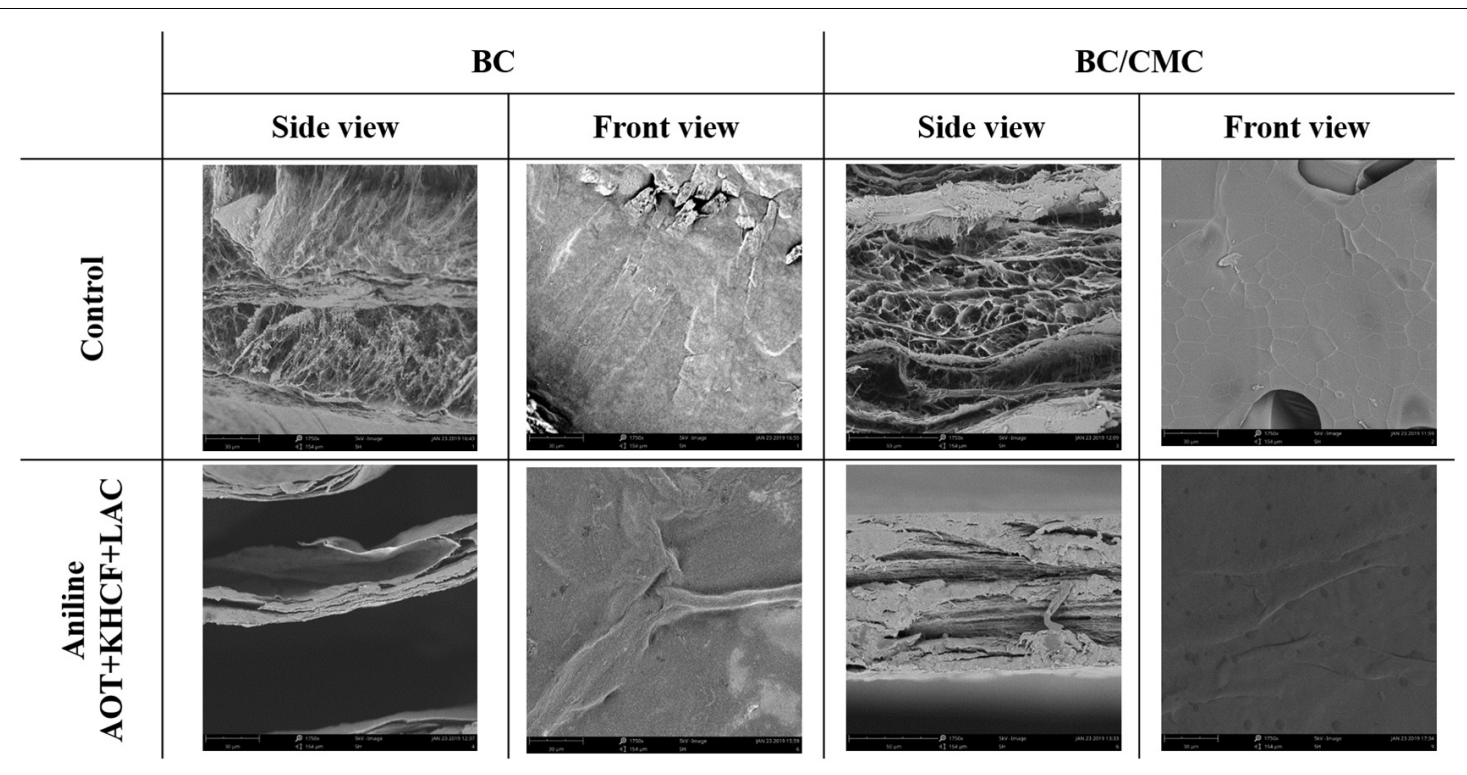

FIGURE 6 | SEM photographs of BC and BC/CMC functionalized with PANi in the presence of laccase and additives ( $\times 1750$ magnification).

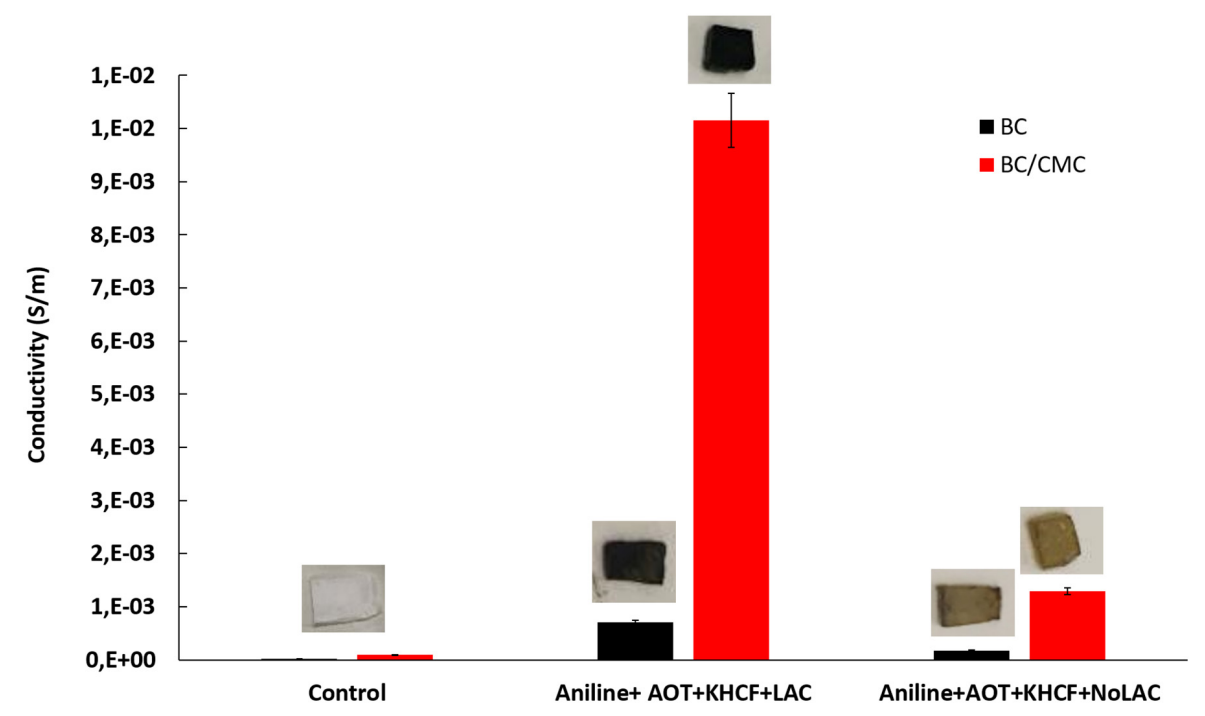

FIGURE 7 | Conductivity of BC and BC/CMC functionalized with polyaniline oxidized by laccase in the presence of additives, AOT and KHCF; images of the samples are presented in the upper part of each graph bar.

BC (comparing black line with red line), when PANi is inside BC (black dot and dash lines) the packing of the cellulose chains can be more disorganized, leading to lower thermostability.

In Table $\mathbf{4}$ are presented in detail the thermal events occurred during TGA analysis, namely the decomposition temperatures $\left(\mathrm{T}_{d \max }\right)$ and respective weight loss $(\Delta$ weight) of the $\mathrm{BC}$ and $\mathrm{BC} / \mathrm{CMC}$ functionalized with PANi.

\section{Surface Morphology}

SEM micrographs of BC and BC/CMC functionalized with PANi in the presence of laccase and additives are presented in Figure 6.
The surface of all samples discloses the characteristic highly porous three-dimensional network of cellulose, responsible for the excellent mechanical properties of the biopolymer, as well as for the high water absorption capacity and liquid retention.

Though the crosslinking density of the cellulosic network has become denser in the BC/CMC composites, they did not exhibit a remarkable change in the nanofibers morphology in what concern length and thickness comparing to neat BC membranes. Moreover, CMC incorporation into BC nanofibers led to the reduction of the composites' porosity as a simple result of the diffusion of $\mathrm{CMC}$ in the BC membrane. 
TABLE 5 | Color evaluation of BC and BC/CMC samples after aniline oxidation by laccase.

\begin{tabular}{lcc}
\hline & & K/S (Checksum) \\
\hline BC & - & 1.99 \\
& Aniline + AOT + KHCF + LAC & 282.32 \\
BC/CMC & Aniline + AOT + KHCF + No LAC & 88.06 \\
& Aniline + AOT + KHCF + LAC & 0.61 \\
& Aniline + AOT + KHCF + No LAC & 341.83 \\
& & 74.94 \\
\hline
\end{tabular}

The surface of BC/CMC by front view reveals a smoother and more compact structure than BC. The higher conversion capacity of $\mathrm{BC} / \mathrm{CMC}$ may have resulted from the wider dimension of fibrils and larger pore dimension of the network, which provided more spaces for PANi deposition and incremented the area available for enzyme-catalyzed reactions (Fu et al., 2015).

\section{Electrical Conductivity and Coloration of $\mathrm{BC}$ and $\mathrm{BC} / \mathrm{CMC}$ Functionalized With PANi}

Figure 7 shows the electrical conductivity and color evaluation of $\mathrm{BC}$ and $\mathrm{BC} / \mathrm{CMC}$ functionalized with PANi. The conductivity of $\mathrm{BC} / \mathrm{CMC} / \mathrm{PANi}$ is considerable higher than that of $\mathrm{BC} / \mathrm{PANi}$. The CMC template, as mentioned previously, allowed the deposition of higher amount of oligomers/polymers inside the $\mathrm{BC}$ network which conferred not only higher electrical conductivity but also incremented coloration. The negatively charged carboxylate groups of $\mathrm{CMC}$ react by ionic interactions with the protonated amino $\left(-\mathrm{NH}_{2}\right)$ groups of PANi to form biopolymer complex (Peng et al., 2015; Gautam et al., 2018). Electrical conductivity of PANi depends essentially on the degree of polymerization, oxidation state, particle morphology, crystallinity, interior intra-chain interactions and molecular weight. These properties were altered by CMC addition conferring to the composites 10 times higher electrical conductivity (Jasim et al., 2017). Comparing with the previous data reported by Shim et al. (2019a), the use of CMC on the system allowed to increment the conductivity results from $2 \mathrm{E}^{-04}$ to $1 \mathrm{E}^{-02}$, giving a strong evidence of the role of the template on promoting aniline oxidation and production of highly conductive materials.

The images of colored samples confirm the direct correlation between the amount of polymer entrapped inside $\mathrm{BC}$ and the conductivity. The higher is the degree of polymerization and amount of polymer entrapped the higher is the color strength (checksum $K / S$; Table 5).

It is noteworthy that the role of laccase as catalyst in the polymerization of PANi is more evident at this stage. Despite the similarity observed between the oligomers of the soluble phase, obtained in the absence or in the presence of laccase, the data herein presented highlighted the role of laccase as an effective catalysts of aniline polymerization. The oligomers synthetized by laccase, due to the template-assisted reaction, are more retained inside $\mathrm{BC} / \mathrm{CMC}$ than the oligomers produced in its absence, increasing exponentially the coloration of the materials and their conductive behavior (Figure 7 and Table 5).

\section{CONCLUSION}

Herein we study the role of CMC as a template for the enzymatic polymerization of aniline inside BC membranes. The best $\mathrm{CMC}$ entrapment conditions were established according to the highest entrapment yield obtained $\left(75 \mathrm{~g} / \mathrm{L}\right.$ CMC, $1.5 \mathrm{~cm}^{2}$ $\left.\mathrm{BC}, 5 \mathrm{~h}, 55^{\circ} \mathrm{C}\right)$. The oxidation experiments conducted using $\mathrm{BC}$ and $\mathrm{BC} / \mathrm{CMC}$ as supports for aniline polymerization in the presence of additives revealed that the type of oligomers obtained is the same, independently on the use of a template (CMC). It is, however, noteworthy that the presence of this template increments the amount of oligomers entrapped inside $\mathrm{BC}$, as adsorbed or bond to the network structure. The template promotes the fixation of higher amount of $\mathrm{PANi}$ to $\mathrm{BC}$ porous structure, incrementing the electrical conductivity and coloration of the materials. The best conditions to produce electrically conductive $\mathrm{BC} / \mathrm{CMC}$ were found to be: $25 \mathrm{U} / \mathrm{mL}$ of laccase, $5 \mathrm{mM}$ of AOT, $10 \mathrm{mM}$ of KHCF, $50 \mathrm{mM}$ of aniline, in acetate buffer ( $\mathrm{pH} 4$ ), for $24 \mathrm{~h}$ at $35^{\circ} \mathrm{C}$.

\section{DATA AVAILABILITY STATEMENT}

All datasets generated for this study are included in the article/Supplementary Material.

\section{AUTHOR CONTRIBUTIONS}

ES was responsible for experimental and writing details. JN was responsible for HNMR data curation. AC-P was the co-supervisor of the work. CS was responsible for experimental details and manuscript revision. HK was the supervisor of the work. All authors have read and approved the final version of the manuscript.

\section{FUNDING}

This work has supported by the National Research Foundation of Korea (NRF) grant funded by the Korea Government (MSIT) (No. NRF-2019R1A2C1009217) and by the Portuguese Foundation for Science and Technology (FCT) under the scope of the strategic funding of UIDB/04469/2020 unit and BioTecNorte operation (NORTE-01-0145-FEDER-000004) funded by European Regional Development Fund under the scope of Norte2020 - Programa Operacional Regional do Norte. JN (SFRH/BD/121673/2016) and CS (SFRH/IF/00186/2015) acknowledged FCT - Foundation for Science and Technology for their funding.

\section{SUPPLEMENTARY MATERIAL}

The Supplementary Material for this article can be found online at: https://www.frontiersin.org/articles/10.3389/fbioe.2020. 00438/full\#supplementary-material 


\section{REFERENCES}

Ballesteros, L. F., Cerqueira, M. A., Teixeira, J. A., and Mussatto, S. I. (2018). Production and physicochemical properties of carboxymethyl cellulose films enriched with spent coffee grounds polysaccharides. Int. J. Biol.Macromol. 106, 647-655. doi: 10.1016/j.ijbiomac.2017.08.060

Basavaraja, C., Kim, J. K., and Huh, D. S. (2013). Characterization and temperaturedependent conductivity of polyaniline nanocomposites encapsulating gold nanoparticles on the surface of carboxymethyl cellulose. Mater. Sci. Eng. B 178, 167-173.

Bhadra, S., Kim, N. H., Rhee, K. Y., and Lee, J. H. (2009). Preparation of nanosize polyaniline by solid-state polymerization and determination of crystal structure. Polym. Int. 58, 1173-1180.

Casaburi, A., Rojo, ÚM., Cerrutti, P., Vázquez, A., and Foresti, M. L. (2018). Carboxymethyl cellulose with tailored degree of substitution obtained from bacterial cellulose. Food Hydrocoll. 75, 147-156.

Chen, S., Zou, Y., Yan, Z., Shen, W., Shi, S., Zhang, X., et al. (2009). Carboxymethylated-bacterial cellulose for copper and lead ion removal. J. Hazard. Mater. 161, 1355-1359. doi: 10.1016/j.jhazmat.2008.04.098

Chen, Y., Zhou, X., Lin, Q., and Jiang, D. (2014). Bacterial cellulose/gelatin composites: in situ preparation and glutaraldehyde treatment. Cellulose 21, 2679-2693.

De Salas, F., Pardo, I., Salavagione, H. J., Aza, P., Amougi, E., Vind, J., et al. (2016). Advanced synthesis of conductive polyaniline using laccase as biocatalyst. PloS One 11:e0164958. doi: 10.1371/journal.pone.0164958

Feng, Y., Zhang, X., Shen, Y., Yoshino, K., and Feng, W. (2012). A mechanically strong, flexible and conductive film based on bacterial cellulose/graphene nanocomposite. Carbohyd. Polym. 87, 644-649.

Fu, J., Pang, Z., Yang, J., Huang, F., Cai, Y., and Wei, Q. (2015). Fabrication of polyaniline/carboxymethyl cellulose/cellulose nanofibrous mats and their biosensing application. Appl. Surface Sci. 349, 35-42.

Gautam, V., Singh, K. P., and Yadav, V. L. (2018). Preparation and characterization of green-nano-composite material based on polyaniline, multiwalled carbon nano tubes and carboxymethyl cellulose: for electrochemical sensor applications. Carbohyd. Polym. 189, 218-228. doi: 10.1016/j.carbpol.2018.02.029

Han, J., Shim, E., and Kim, H. R. (2018). Effects of cultivation, washing, and bleaching conditions on bacterial cellulose fabric production. Text. Res. J. 89, 1094-1104.

Hu, W., Chen, S., Yang, Z., Liu, L., and Wang, H. (2011). Flexible electrically conductive nanocomposite membrane based on bacterial cellulose and polyaniline. J. Phys. Chem. B 115, 8453-8457. doi: 10.1021/jp204422v

Jasim, A., Ullah, M. W., Shi, Z., Lin, X., and Yang, G. (2017). Fabrication of bacterial cellulose/polyaniline/single-walled carbon nanotubes membrane for potential application as biosensor. Carbohyd. Polym. 163, 62-69. doi: 10.1016/j.carbpol. 2017.01.056

Kim, Y., Uyama, H., and Kobayashi, S. (2004). Enzymatic template polymerization of phenol in the presence of water-soluble polymers in an aqueous medium. Polym. J. 36, 992.

Kotresh, S., Ravikiran, Y., Prakash, H. R., Ramana, C. V., Vijayakumari, S., and Thomas, S. (2016). Humidity sensing performance of spin coated polyanilinecarboxymethyl cellulose composite at room temperature. Cellulose 23, 31773186.

Lin, Q., Zheng, Y., Ren, L., Wu, J., Wang, H., An, J., et al. (2014). Preparation and characteristic of a sodium alginate/carboxymethylated bacterial cellulose composite with a crosslinking semi-interpenetrating network. J. Appl. Polym. Sci. 131, 39848-39856.

Lin, Q., Zheng, Y., Wang, G., Shi, X., Zhang, T., Yu, J., et al. (2015). Protein adsorption behaviors of carboxymethylated bacterial cellulose membranes. Int. J. Biol. Macromol. 73, 264-269. doi: 10.1016/j.ijbiomac.2014.11.011

Lopes, T. D., Riegel-Vidotti, I. C., Grein, A., Tischer, C. A., and de Sousa FariaTischer, P. C. (2014). Bacterial cellulose and hyaluronic acid hybrid membranes: production and characterization. Int. J. Biol. Macromol. 67, 401-408. doi: 10. 1016/j.ijbiomac.2014.03.047

Marins, J. A., Soares, B. G., Dahmouche, K., Ribeiro, S. J., Barud, H., and Bonemer, D. (2011). Structure and properties of conducting bacterial cellulose-polyaniline nanocomposites. Cellulose 18, 1285-1294.
Miyamoto, H., Tsuduki, M., Ago, M., Yamane, C., Ueda, M., and Okajima, K. (2014). Influence of dyestuffs on the crystallinity of a bacterial cellulose and a regenerated cellulose. Text. Res. J. 84, 11471158.

Mohammadkazemi, F., Azin, M., and Ashori, A. (2015). Production of bacterial cellulose using different carbon sources and culture media. Carbohyd. Polym. 117, 518-523. doi: 10.1016/j.carbpol.2014.10.008

Müller, D., Mandelli, J., Marins, J., Soares, B., Porto, L., Rambo, C., et al. (2012). Electrically conducting nanocomposites: preparation and properties of polyaniline (PAni)-coated bacterial cellulose nanofibers (BC). Cellulose 19, $1645-1654$.

Norris, I. D., Shaker, M. M., Ko, F. K., and MacDiarmid, A. G. (2000). Electrostatic fabrication of ultrafine conducting fibers: polyaniline/polyethylene oxide blends. Synth. Met. 114, 109-114.

Peng, H., Ma, G., Sun, K., Mu, J., Zhou, X., and Lei, Z. (2015). A novel fabrication of nitrogen-containing carbon nanospheres with high rate capability as electrode materials for supercapacitors. Rsc Adv. 5, 1203412042.

Peng, H., Ma, G., Ying, W., Wang, A., Huang, H., and Lei, Z. (2012). In situ synthesis of polyaniline/sodium carboxymethyl cellulose nanorods for highperformance redox supercapacitors. J. Power Sour. 211, 40-45.

Pushpamalar, V., Langford, S., Ahmad, M., and Lim, Y. (2006). Optimization of reaction conditions for preparing carboxymethyl cellulose from sago waste. Carbohyd. Polym. 64, 312-318.

Sadeghi, M., Ghasemi, N., and Soliemani, F. (2012). Graft copolymerization methacrylamide monomer onto carboxymethyl cellulose in homogeneous solution and optimization of effective parameters. World Appl. Sci. J. 16, $119-125$.

Sapurina, I. Y., and Shishov, M. (2012). "Oxidative polymerization of aniline: molecular synthesis of polyaniline and the formation of supramolecular structures," in New Polymers for Special Applications, ed. A. D. S. Gomes (London: IntechOpen), 251-312.

Shah, A. U. H. A., Kamran, M., Bilal, S., and Ullah, R. (2019). Cost effective chemical oxidative synthesis of soluble and electroactive polyaniline salt and its application as anticorrosive agent for steel. Materials 12:1527. doi: 10.3390/ ma12091527

Shim, E., and Kim, H. R. (2019). Coloration of bacterial cellulose using in situ and ex situ methods. Text. Res. J. 89, 1297-1310.

Shim, E., Noro, J., Cavaco-Paulo, A. M., Silva, C., and Kim, H. R. (2019a). Effect of additives on the in situ enzyme-catalyzed polymerization of aniline onto bacterial cellulose. Front. Bioeng.Biotechnol. 7:64. doi: 10.3389/fbioe.2019.00264

Shim, E., Su, J., Noro, J., Teixeira, M. A., Cavaco-Paulo, A., Silva, C., et al. (2019b). Conductive bacterial cellulose by in situ laccase polymerization of aniline. PloS One 14:e0214546. doi: 10.1371/journal.pone.0214546

Shumakovich, G., Kurova, V., Vasil'eva, I., Pankratov, D., Otrokhov, G., Morozova, O., et al. (2012). Laccase-mediated synthesis of conducting polyaniline. J. Mol. Catal.B Enzym. 77, 105-110.

Song, J. E., Su, J., Loureiro, A., Martins, M., Cavaco-Paulo, A., Kim, H. R., et al. (2017). Ultrasound-assisted swelling of bacterial cellulose. Eng. Life Sci. 17, $1108-1117$.

Streltsov, A. V., Morozova, O. V., Arkharova, N. A., Klechkovskaya, V. V., Staroverova, I. N., Shumakovich, G. P., et al. (2009). Synthesis and characterization of conducting polyaniline prepared by laccase-catalyzed method in sodium dodecylbenzenesulfonate micellar solutions. J. Appl., Polyme. Sci. 114, 928-934.

Su, J., Noro, J., Loureiro, A., Martins, M., Azoia, N. G., Fu, J., et al. (2017). PEGylation greatly enhances laccase polymerase activity. Chemcatchem 9, 3888-3894.

Su, J., Shim, E., Noro, J., Fu, J., Wang, Q., Kim, H. R., et al. (2018). Conductive cotton by in situ laccase-polymerization of aniline. Polymers 10:1023. doi: 10. 3390/polym 10091023

Walde, P., Kashima, K., and Æiriæ-Marjanoviæ, G. (2019). Synthesizing polyaniline with Laccase/O2 as catalyst. Front. in Bioeng. Biotechnol. 7:165. doi: 10.3389/fbioe.2019.00165

Wan, Y., Hong, L., Jia, S., Huang, Y., Zhu, Y., Wang, Y., et al. (2006). Synthesis and characterization of hydroxyapatite-bacterial cellulose nanocomposites. Compos. Sci. Technol. 66, 1825-1832. 
Wang, F., Jeon, J., Park, S., Kee, C., Kim, S., and Oh, I. (2016). A soft biomolecule actuator based on a highly functionalized bacterial cellulose nano-fiber network with carboxylic acid groups. Soft Matter 12, 246-254. doi: 10.1039/c5sm00 $707 \mathrm{k}$

Yamamoto, H., Horii, F., and Hirai, A. (1996). In situ crystallization of bacterial cellulose II. influences of different polymeric additives on the formation of celluloses I $\alpha$ and I $\beta$ at the early stage of incubation. Cellulose 3, $229-242$.

Yousefi, H., Faezipour, M., Hedjazi, S., Mousavi, M. M., Azusa, Y., and Heidari, A. H. (2013). Comparative study of paper and nanopaper properties prepared from bacterial cellulose nanofibers and fibers/ground cellulose nanofibers of canola straw. Indus. Crops Prod. 43, 732-737.

Yue, L., Zheng, Y., Xie, Y., Liu, S., Guo, S., Yang, B., et al. (2016). Preparation of a carboxymethylated bacterial cellulose/polyaniline composite gel membrane and its characterization. Rsc $A d v$. 6, 68599-68605.
Zhang, Y., Fan, X., Wang, Q., and Cavaco-Paulo, A. (2016). Preparation of functionalized cotton based on laccase-catalyzed synthesis of polyaniline in perfluorooctanesulfonate acid potassium salt (PFOS) template. RSC Adv. 6, $49272-49280$

Conflict of Interest: The authors declare that the research was conducted in the absence of any commercial or financial relationships that could be construed as a potential conflict of interest.

Copyright $\odot 2020$ Shim, Noro, Cavaco-Paulo, Kim and Silva. This is an open-access article distributed under the terms of the Creative Commons Attribution License (CC BY). The use, distribution or reproduction in other forums is permitted, provided the original author(s) and the copyright owner(s) are credited and that the original publication in this journal is cited, in accordance with accepted academic practice. No use, distribution or reproduction is permitted which does not comply with these terms. 